\begin{tabular}{|c|c|}
\hline UÁQUIRI & PPG \\
\hline & Revista do Programa de Pós-Graduação em Geografia \\
UÁQUIRI - PPGGEO, v. 2, n. 2, p. 61-79, ano 2020 \\
Home page: https://periodicos.ufac.br/index.php/Uaquiri
\end{tabular}

\title{
PERCEPÇÃO DE RISCO DOS MORADORES DE ÁREA COM INUNDAÇÕES RECORRENTES: ANÁLISE NOS BAIRROS DA BAIXADA DO SOBRAL - RIO BRANCO/AC ${ }^{1}$
}

\author{
Aniely Souza de Araújo ${ }^{1 *}$, Gabriel Aguiar da Silva ${ }^{1}$, Michel Felix da Silva ${ }^{1}$, \\ Fernanda Lima- Silva ${ }^{2}$ \\ ORCID: https://orcid.org/0000-0002-9973-4201; https://orcid.org/0000-0003-2540-9518; \\ https://orcid.org/0000-0001-8080-0427; https://orcid.org/0000-0003-4838-7075 \\ ${ }^{1}$ Universidade Federal do Acre, Graduação em Geografia, Rio Branco, Acre, Brasil. \\ ${ }^{2}$ Centro de Estudos em Administração Pública e Governo da Fundação Getúlio Vargas - Escola de \\ Administração de Empresas de São Paulo (CEAPG/FGV EAESP), São Paulo, Brasil. \\ *anniely.wanda.rosa@gmail.com
}

Recebido em: 26/05/2020; Aceito em: 04/07/2020; Publicado em: 20/12/2020

DOI: https://doi.org/10.47418/uaquiri.vol2.n2.2020.3742

\begin{abstract}
RESUMO
O Brasil é um dos países mais afetados por inundações, as quais resultam em danos materiais e elevado número de pessoas atingidas. A chuva é frequentemente vista como a principal causa deste fenômeno. No entanto, entender a dinâmica deste evento requer olhar para uma combinação de fatores: ocupação desordenada do território, acúmulo de lixo e entulho nos rios e córregos, falhas no planejamento urbano e possíveis mudanças climáticas. Especialistas indicam que, para lidar com as inundações, é essencial contar com sistemas adequados de gerenciamento de risco, que identifiquem as áreas mais vulneráveis, viabilizem planos de prevenção e resposta a desastres e promovam, sobretudo, o engajamento de moradores das áreas mais expostas. A participação da população desses territórios é, portanto, parte essencial desse processo e está diretamente vinculada com a forma pela qual as pessoas percebem os riscos de desastre. Isto posto, o objetivo desta pesquisa é analisar a percepção de moradores de uma área com histórico de inundações recorrentes, os bairros da Baixada do Sobral, em Rio Branco. Embora existam diversos estudos sobre as inundações nesta cidade, dada a longa trajetória de eventos registrados, poucas pesquisas abordam especificamente a percepção de residentes sobre o risco de ocorrência e formas de prevenção. Os resultados obtidos indicam que os moradores da área pesquisada entendem as inundações como um fenômeno cotidiano e adotam diferentes estratégias de prevenção em relação aos seus efeitos. Além disso, apontam que esta população tem acesso reduzido a dados oficiais sobre chuvas e níveis do rio e estão pouco inseridos no sistema local de governança de risco de inundação, o que reforça sua vulnerabilidade a este tipo de fenômeno socioambiental. A consecução do estudo evidencia a necessidade de promover o aprimoramento e intensificação das ações de prevenção, planejamento e preparo dos vários setores envolvidos nos desastres e, principalmente, o envolvimento da comunidade suscetível e vulnerável.
\end{abstract}

\footnotetext{
${ }^{1}$ Este artigo é resultado de uma pesquisa em andamento do projeto Dados à prova d'água (Waterproofing Data WPD, em inglês), uma pesquisa multidisciplinar que discute a governança dos riscos de inundações com foco nos aspectos sociais e culturais das práticas de dados.
} 
Palavras-chave: Percepção de risco; Vulnerabilidade; Inundações.

\title{
PERCEPTION OF RISK FROM DWELLERS OF AREA WITH RECURRING FLOODS: ANAL YSIS OF BAIXADA DO SOBRAL - RIO BRANCO / AC
}

\begin{abstract}
Brazil is one of the countries most affected by floods, which results in material damage and a high number of people affected. Rain is often seen as the main cause of this phenomenon. However, understanding the dynamics of this event requires looking at a combination of factors: the disorderly occupation of the territory, accumulation of garbage and debris in rivers and streams, failures in urban planning and possible climate changes. Experts indicate that to deal with floods, it is essential to have adequate risk management systems, which identify the least vulnerable areas, enable disaster prevention and response plans and, above all, promote the engagement of residents in the most exposed areas. The participation of the population of these territories is, therefore, an essential part of this process and is directly linked to how people perceive the risks of disaster. That said, the objective of this research is to analyze the perception of residents of an area with a history of recurrent flooding, the Baixada do Sobral neighborhoods, in Rio Branco. Although there are several studies on floods in this city, given the long history of recorded events, few studies specifically address residents' perceptions of the risk of occurrence and ways of prevention. The results obtained indicate that the residents of the researched area understand floods as a daily phenomenon and adopt different prevention strategies concerning their effects. Also, they point out that this population has reduced access to official data on rainfall and river levels and are little inserted in the local flood risk governance system, which reinforces their vulnerability to this type of socio-environmental phenomenon. The completion of the study highlights the need to promote the improvement and intensification of the prevention, planning and preparation actions of the various sectors involved in disasters and, mainly, the involvement of the susceptible and vulnerable community.
\end{abstract}

Keywords: Risk Perception; Vulnerability; Floods.

\section{PERCEPCIÓN DE RIESGO EN COMUNIDADES CON INUNDACIONES FRECUENTES: ANÁLISIS DE LA BAIXADA DO SOBRAL - RIO BRANCO / AC}

\section{RESUMEN}

Brasil es uno de los países más afectados por las inundaciones, lo que resulta en danos materiales y em una gran cantidad de personas afectadas. La lluvia es a menudo vista como la principal causa de este fenómeno. Sin embargo, comprender la dinámica de este evento requiere una combinación de factores: ocupación desordenada del territorio, acumulación de basura y escombros en ríos y arroyos, fallas en la planificación urbana y posibles cambios climáticos. Los expertos indican que, para hacer frente a las inundaciones, es esencial contar con sistemas adecuados de gestión de riesgos, que identifiquen las áreas menos vulnerables, permitan la prevención de desastres y planes de respuesta y, sobre todo, promuevan la participación de los residentes en las áreas más expuestas. Por lo tanto, la participación de la población en estos territorios es una parte esencial de este proceso y está directamente relacionada con la forma en que las personas perciben los riesgos de un desastre. Dicho esto, el objetivo de esta investigación es analizar la percepción de los residentes de un área con antecedentes de inundaciones recurrentes, en los barrios de Baixada do Sobral, en Río Branco. Aunque hay varios estudios sobre inundaciones en esta ciudad, dada la larga historia de eventos registrados, pocos estudios abordan específicamente las percepciones de los residentes sobre el riesgo de ocurrencia y las formas de prevención. Los resultados obtenidos indican que los residentes del área investigada entienden las inundaciones como un fenómeno diario y adoptan diferentes estrategias de prevención en relación con sus efectos. Además, señalan que esta población ha reducido el acceso a datos oficiales sobre las precipitaciones y los niveles de los ríos $\mathrm{y}$ es una pequeña parte del sistema local de gobernanza del riesgo de inundaciones, lo que refuerza su 
vulnerabilidad a este tipo de fenómeno socioambiental. La conclusión del estudio destaca la necesidad de promover la mejora e intensificación de las acciones de prevención, planificación y preparación de los diversos sectores involucrados en desastres y, principalmente, la participación de la comunidad susceptible y vulnerable.

Palabras clave: Baixada da Sobral; Percepción; Vulnerabilidad; Arañazos; e inundaciones.

\section{INTRODUÇÃO}

Desastres estão relacionados ao cotidiano da humanidade desde as primeiras civilizações. De acordo com a Estratégia Internacional para a Redução de Desastres da Organização das Nações Unidas (EIRD/ONU), eles representam a suspensão da normalidade de comunidades ou sociedades, gerando impactos ambientais e sociais, como perdas humanas, materiais e econômicas, dificultando que essas pessoas lidem por conta própria com essas situações.

No entanto, situações de desastres estão se tornando cada vez mais recorrentes e prejudiciais. É urgente reconhecer que os desastres não são naturais (WISNER et al., 2011). Mesmo quando um evento extremo é gerado por forças da natureza, ele somente se torna um desastre socioambiental quando tem impactos e gera danos para a sociedade (TRAJBER, 2019). As causas do aumento na frequência e na intensidade dos desastres socioambientais envolvem a crescente intervenção humana na natureza e a expansão exponencial das cidades e da população mundial, afetando de forma mais intensa as comunidades pobres das periferias urbanas, que frequentemente vivem em áreas de risco.

Diante de tal complexidade, é impreterível que governos locais e sociedade civil se orientem por uma gestão integrada de risco de desastres, baseada em atividades de prevenção, mitigação, preparação, resposta e recuperação (LONDE et al., 2014). Por isso é importante compreender as possibilidades e os processos de prevenção de risco e promover o engajamento de diferentes atores locais, como a Defesa Civil municipal e a população residente em áreas mais vulneráveis ao evento.

As inundações são uma das formas de desastres mais frequentes no mundo. Segundo Freitas e Ximenes (2012), elas afetam cerca de 102 milhões de pessoas por ano e tem se tornado maiores e mais frequentes por conta das mudanças climáticas, tema de relevante interesse da comunidade científica e instituições em geral. As inundações ocorrem devido à associação de causas antrópicas e eventos extremos da natureza e representam graves problemas ambientais, mas também sociais. 
No que tange aos impactos sociais das inundações, é crucial destacar que a repercussão dos episódios pluviais intensos se dá de forma desigual, social e territorialmente. Estes eventos têm um significado diferente para a pessoa que teve sua casa atingida, para outra que ficou presa no ônibus e para quem assistiu tudo pelos meios de comunicação. Portanto, faz-se necessário compreender as dimensões culturais, políticas, sociais e econômicas do problema das inundações, assim como iluminar como a população mais vulnerável percebe o fenômeno e se engaja em sua prevenção.

Este estudo se concentra na cidade de Rio Branco, estado do Acre, que possui vários bairros suscetíveis aos efeitos das enchentes, visto que se localizam em áreas da planície de inundação do rio Acre. Estas regiões abrigam grande parte da população de baixa renda, que fica, portanto, mais exposta aos impactos de tais eventos. Neste contexto, existem vários estudos sobre as enchentes, todavia, não se verificou registro de pesquisas que abordem especificamente a perspectiva dos moradores sobre riscos de inundações, estratégias de prevenção e gestão integrada. Os estudos existentes enfatizam temas variados, como as situações de vulnerabilidade e risco ambiental a que estão expostas populações residentes em ocupações precárias (ALVES, 2017), a atuação governamental em momentos de inundações (SANTOS, 2006), as formas de ação e a percepção dos atores governamentais e não governamentais envolvidos com a gestão de risco de inundações em Rio Branco (NETO, 2015; MESQUITA, 2015) e a cobertura midiática das inundações (SANTOS et al., 2017).

Este texto está estruturado em cinco seções. Inicialmente, é apresentado o debate sobre riscos e vulnerabilidades a inundações no Brasil, incluindo reflexões sobre a percepção e o envolvimento da população no gerenciamento local de riscos. A segunda parte relata a estratégia metodológica utilizada na realização do trabalho. Em seguida é descrito o território em que a pesquisa está sendo desenvolvida, a Baixada do Sobral. Na quarta seção, intitulada "Resultados e discussões", são apresentados os resultados das análises das entrevistas realizadas com moradores da área de estudo. Por fim, nas considerações finais, são apresentadas as reflexões sobre os resultados do trabalho.

\section{RISCOS DE INUNDAÇÕES NO BRASIL}

O modelo contemporâneo de sociedade requer a utilização de técnicas de gestão dos riscos de desastres, dado que eles estão se tornando mais intensos e comuns. Mas o que são riscos? Riscos são situações complexas e multifatoriais que que podem ser entendidos a partir da relação entre ameaça, vulnerabilidade e capacidade de enfrentamento (WISNER et al., 
2011). A ameaça pode ter origem biológica (como epidemias e pandemias virais), tecnológica (por exemplo, o rompimento de barragens) e física (como terremotos e chuvas).

O presente estudo enfatiza o risco relacionado a eventos hidrológicos extremos. Neste sentido, estima-se que o número de pessoas que vivem expostas ao perigo proveniente da materialização de eventos de enchentes atinge a marca de um bilhão, e que os registros devem alcançar a casa de dois bilhões em 2050 (SPINK, 2014). O Brasil é um dos países mais afetados por inundações, resultando em elevado número de pessoas afetadas e mortes (LONDE et al, 2014). Como exemplos recentes, destacam-se as inundações e deslizamentos de terra no Rio de Janeiro registrados em 2019 (GRADIN, 2019) e em 2020 na cidade de São Paulo (SANT'ANNA et al., 2020), além da grande inundação em Rio Branco em 2015 (SANTOS et al., 2017).

Enchentes, inundações, alagamentos são conceitos frequentemente usados e relacionados com eventos hídricos extremos, sendo importante defini-los. A figura 1 apresenta uma representação visual das diferenças entre estes conceitos. De acordo com Londe et al. (2014), enchente é a elevação temporária do nível d'água em um canal de drenagem devido ao aumento da vazão ou descarga, enquanto inundação é o processo de extravasamento das águas do canal de drenagem para as áreas marginais (planície de inundação, várzea ou leito maior do rio).

Figura 1: Perfil esquemático do processo de enchente e inundação

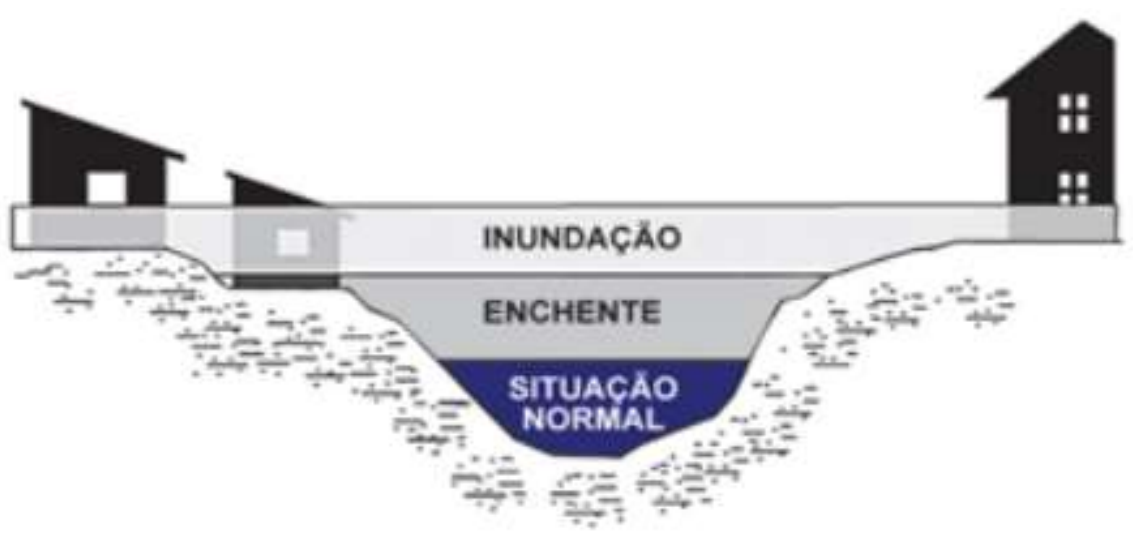

Fonte: Brasil (2007, p. 92).

A noção de alagamento é usada para tratar do acúmulo momentâneo de águas em uma determinada área urbana por problemas associados à drenagem, podendo (ou não) estar associado a processos de natureza fluvial. No entanto, no contexto acreano, o termo "alagação" 
é frequentemente utilizado para se referir às inundações. Segundo Mesquita (2015, p. 53), “[...] o termo "alagação" é regionalmente conhecido e adotado pela população e inclusive é vinculado com ênfase nas mídias digitais e em sites oficiais da prefeitura e governo do Estado do Acre".

Apesar do histórico de inundações, o Brasil segue sofrendo com este tipo de desastre socioambiental ano após ano. No país, o gerenciamento destes desastres ainda enfrenta muitos desafios. Muitos são os problemas encontrados na estrutura da Defesa Civil dos municípios. Na cidade de Rio Branco, por exemplo, Santos (2006) destaca a estrutura organizacional subsistente, recursos humanos escassos e deficiência orçamentária financeira. Além disso, é necessário aprimorar a comunicação entre os representantes voluntários de bairros e a Defesa Civil, bem como potencializar a participação comunitária para a redução de riscos e para a construção de resiliência, fatores que impactam na resposta necessária aos desastres (FORESTI, 2015).

É importante, novamente, destacar que os desastres não afetam as pessoas de forma homogênea, uma vez que eles potencializam as vulnerabilidades já existentes no território, o que pode ser depreendido no trecho a seguir:

\footnotetext{
A vulnerabilidade corresponde a um conjunto de condições sociais, econômicas, políticas, culturais, técnicas, educativas e ambientais que deixam as pessoas mais expostas ao perigo. Em outras palavras, ser vulnerável é estar fisicamente sensível a uma ameaça/perigo e apresentar fragilidade diante do dano (TRAJBER et al., s.d., p. 6).
}

Muitas das áreas com mais elevada vulnerabilidade a inundações, como a Baixada do Sobral, tem como características serem fruto de ocupações urbanas pouco planejadas e estarem localizadas em áreas ambientalmente sensíveis. As pessoas residentes nestes territórios estão mais expostas ao impacto dos desastres do que populações que vivem em áreas formais e com acesso adequado a serviços públicos e a infraestrutura urbana.

\subsection{GESTÃO DE RISCOS DE INUNDAÇÃO E PARTICIPAÇÃO COMUNITÁRIA}

A gestão de riscos é a terminologia utilizada para definir um conjunto de ações estratégicas, como identificação, administração, condução, prevenção e gerenciamento dos riscos (TRAJBER et al., s.d. p. 7). Tratando especificamente do gerenciamento de risco de desastres socioambientais, algumas etapas são imprescindíveis para se antecipar a problemas e tomar decisões adequadas e céleres. De acordo com Gusman (2003), é necessário (i) identificar a natureza, a extensão e o risco de ameaça; (ii) determinar a existência e o grau de vulnerabilidades; (iii) identificar as capacidades e os recursos disponíveis; (iv) determinar os 
níveis aceitáveis de risco, bem como os de custo-benefício; (v) definir prioridades em relação ao tempo, recursos de alocação e eficácia dos resultados; (vi) desenvolver métodos de proteção de pessoas e recursos-chave para redução de perdas globais e (vii) criar sistemas eficazes e adequados de gestão a serem implementados e controlados.

$\mathrm{Na}$ formulação e implantação de políticas públicas, de modo geral, e também na gestão local de risco de desastre, a participação comunitária é considerada um fator essencial. Ela pode garantir maior legitimidade e fortalecer a governabilidade. Entretanto, o engajamento comunitário em políticas públicas e na gestão local de risco de inundações se relaciona com as formas pelas quais a população percebe tais riscos. O conceito de 'percepção' advém de uma palavra de origem latina relacionada com a tomada de consciência, de forma nítida, a respeito de qualquer objeto ou circunstância. Pode-se interpretar que o risco ambiental depende das diferentes formas de percepção individual ou coletiva sobre um fenômeno determinado:

\footnotetext{
No caso específico das inundações, fatores cognitivos, comportamentais, socioeconômicos, demográficos, geográficos, informacionais e culturais são elementos chave para determinar os critérios levados em conta, e precisam integrar o processo de análise das percepções e hierarquizações dos riscos (SILVA et al, no prelo, p. 02).
}

Cabe ressaltar que a reação e a percepção ao risco estão diretamente associadas. A reação que um indivíduo apresenta diante do risco de inundação vincula-se à percepção que ele desenvolveu sobre ela. Relaciona-se à consciência que se tem sobre a gravidade das consequências a ela associadas, ao cenário de destruição por eles imaginado. Assim, como identificado por Neto (2015) ao analisar a percepção de diferentes atores vinculados com a inundação de 2015, em Rio Branco, e também por Silva et al. (no prelo), não é incomum haver dissonâncias na percepção de risco quando se consideram os gestores públicos e residentes de áreas afetadas por inundações, moradores de um mesmo bairro ou de áreas distintas da mesma cidade.

Para adotar as melhores estratégias na gestão de risco de inundação, faz-se necessário conhecê-lo o melhor possível e também valorizar as percepções das comunidades envolvidas, pois os moradores convivem cotidianamente com os riscos e são eles que conhecem suas reais necessidades.

\section{MÉTODO DE ABORDAGEM}

A pesquisa foi baseada em uma abordagem qualitativa, utilizando-se de diferentes estratégias para coleta de dados, como revisão da literatura, análise de reportagens na mídia 
local, revisão dos diários de campo escritos pelos pesquisadores e desenvolvimento de entrevistas semi-estruturadas com moradores da área de estudo, o bairro Baixada do Sobral.

Optou-se por entrevistas semi-estruturadas, pois elas possibilitam, ao mesmo tempo, que o pesquisador obtenha alguma padronização e flexibilidade na condução das perguntas. Assim, ao roteiro de entrevistas foram acrescentadas outras perguntas com base no perfil do entrevistado/a e na dinâmica da conversa. Trabalhou-se com um questionário com nove questões, que podem ser visualizadas no Anexo 1.

O desenvolvimento das entrevistas fundamentou-se nos princípios do método snowball sampling, ou, bola de neve. De acordo com Vinuto (2014), trata-se de uma técnica de amostragem não probabilística, que tem início com um pequeno grupo, denominado "semente", responsável por convidar ou indicar outras pessoas para participarem, ou seja, uma forma de criar uma cadeia de referências para a realização da pesquisa. Sobre a utilização de tal método, destaca-se que ele é recomendado:

[...] principalmente para fins exploratórios, usualmente com três objetivos: desejo de melhor compreensão sobre um tema, testar a viabilidade de realização de um estudo mais amplo, e desenvolver os métodos a serem empregados em todos os estudos ou fases subsequentes (VINUTO, 2014, p. 205).

Para Vinuto (2014), técnicas de caráter qualitativo, como entrevistas e rodas de conversas, podem ser utilizadas em conjunto com esse método, como nesta pesquisa. Em um primeiro momento foram realizadas entrevistas com os moradores que aceitaram participar e haviam sido previamente contactados. No final dessas entrevistas, foi perguntado se ele/a poderia indicar outra pessoa, e assim chegou-se a alguns presidentes de bairro, que têm influência e conhecimento sobre o local, sendo atores chaves para facilitar a entrada nos mais diversos grupos sociais dos bairros estudados.

Para fins desta pesquisa, foram entrevistadas 10 pessoas que moram na Baixada da Sobral: 5 mulheres e 5 homens, com idades que variaram entre 36 e 63 anos. Do total de respondentes, 6 não tinham envolvimento ou atuação comunitária significativa no momento da entrevista, 1 era vice-presidente de uma associação de moradores e 3 eram presidentes de bairro, tendo sido eleitos pela população como representantes das suas comunidades para exercer o papel de mediador com o poder público local e administrar a associação de moradores dos seus respectivos bairros. Um pequeno resumo do perfil das pessoas entrevistadas é apresentado no quadro 1. 
É importante ressaltar que as técnicas escolhidas para operacionalizar esta pesquisa implicam na construção de uma amostra de conveniência, e não aleatória. Isso significa que não as percepções encontradas nos resultados expressam a realidade do universo pesquisado, mas não podem ser generalizadas para além dele.

Quadro 1: Perfil dos entrevistados

\begin{tabular}{|c|c|c|c|c|}
\hline Identificação & Idade & $\begin{array}{c}\text { Tempo como } \\
\text { Morador }\end{array}$ & Bairro & Alagação \\
\hline Entrevistado $1 *$ & 42 & 6 anos & Boa União & 2 \\
\hline Entrevistado 2 & 62 & 23 anos & Gloria & 1 \\
\hline Entrevistado 3 & 52 & 30 anos & Bahia Nova & 2 \\
\hline Entrevistado $4 *$ & 51 & 30 anos & Bahia Nova & Varias \\
\hline Entrevistado $5 *$ & 50 & 50 anos & $\begin{array}{c}\text { Aeroporto } \\
\text { Velho }\end{array}$ & Varias \\
\hline Entrevistado $6^{*}$ & 39 & 13 anos & Boa União & 3 \\
\hline Entrevistado 7 & 63 & $\begin{array}{l}4 \text { meses na casa atual, } \\
\text { mora no bairro desde a } \\
\text { infância }\end{array}$ & Sobral & 1 \\
\hline Entrevistado 8 & 40 & 10 anos & $\begin{array}{c}\text { Aeroporto } \\
\text { Velho }\end{array}$ & 1 \\
\hline Entrevistado 9 & 36 & $\begin{array}{c}7 \text { anos na casa atual, } \\
\text { mora no bairro desde a } \\
\text { infância }\end{array}$ & Ayrton Sena & 2 \\
\hline Entrevistado 10 & 44 & 30 anos & Ayrton Sena & 2 \\
\hline
\end{tabular}

* Presidente de bairro e vice- presidente.

Todas as entrevistas foram gravadas com o prévio consentimento do participante e transcritas integralmente. Elas aconteceram em março de 2020, com duração de 10 a 25 minutos cada. Durante as entrevistas, foi lido e explicado o Termo de Consentimento Livre e Esclarecido (TCLE) que, além de descrever os objetivos da pesquisa, explicitava a possibilidade de desistir a qualquer momento, bem como deixar de responder a qualquer pergunta. Após a leitura, aqueles que aceitaram participar assinaram o TCLE.

Por fim, considerando que a pesquisa qualitativa, quando comparada aos estudos quantitativos, está sujeita a um maior grau de subjetividade no gerenciamento e análise dos dados, conforme descrito por Beltrão e Nogueira (2011), ela exige o máximo possível de clareza e transparência no relato dos procedimentos adotados pelos pesquisadores para analisar os dados coletados. Primeiramente, foi feita a leitura das transcrições das entrevistas e, em seguida, este material foi detalhadamente analisado e categorizado, utilizando-se os seguintes códigos: atuação comunitária no bairro, tempo de moradia, quantidade de inundações vivenciadas, causas e consequências das inundações, percepção sobre risco de inundação, como se informa/se previne sobre as enchentes. 


\section{A BAIXADA DO SOBRAL}

Rio Branco teve seu processo de formação nas proximidades do rio Acre, pois ele era o principal meio de transporte e de escoamento de produtos, sobretudo de borracha, que foi a base da economia da região até a década de 1970. Quando o sistema extrativista da borracha entrou em crise, o governador Vanderley Dantas decidiu estimular a vinda de grandes empresas, fazendeiros e especuladores de terras para o Acre e, dessa forma, o Estado passou de um sistema econômico baseado no extrativismo para uma economia agrícola (LUCENA, 2016).

A figura 02 indica a localização geográfica do município de Rio Branco, indicando, adicionalmente, seus limites no território do Acre e do Brasil.

Figura 2: Localização do município de Rio Branco no Acre e no Brasil

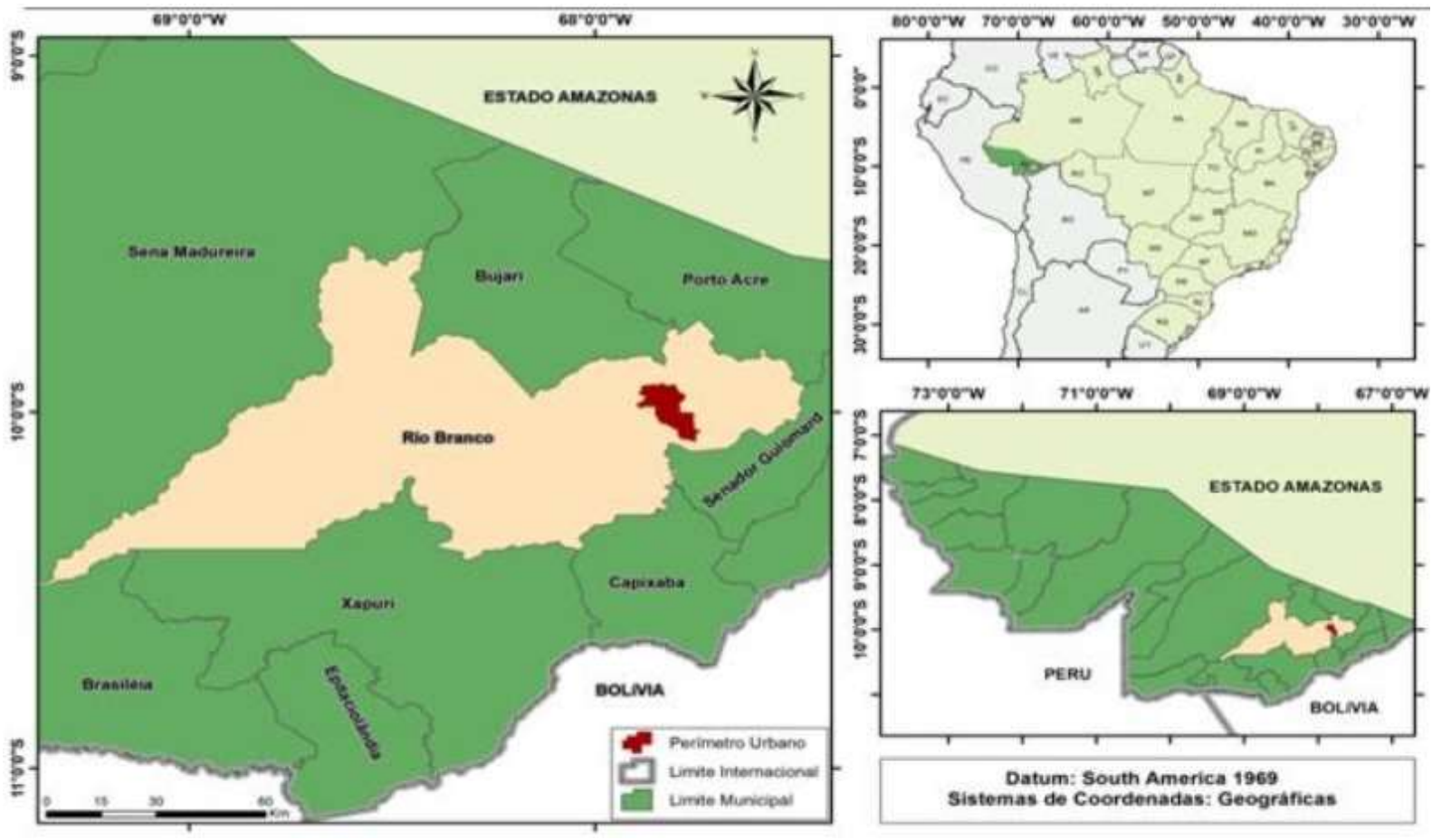

Fonte: Pimentel (2015 apud MESQUITA, 2015, p. 50).

Ainda de acordo com Lucena (2016), nessa época, os seringueiros venderam suas terras para fazendeiros e proprietários de grandes empresas que eram, na sua maioria, pessoas do Sul e Sudeste do país, e o Acre entrou na expansão da fronteira agrícola, iniciando-se um grande fluxo migratório campo-cidade. Em um contexto de exíguas ações governamentais de habitação de interesse social, surgiram inúmeros confrontos entre lideranças populares e grileiros de terras envolvidos em processos de ocupação informal de terrenos na cidade: 
[...] esse novo fluxo migratório campo-cidade promoveu uma verdadeira mudança em Rio Branco, que por sua condição de capital atraiu a maioria dos seringueiros, castanheiros e ribeirinhos expulsos de suas colocações em todo o estado. A partir de então, teve início a prática das "invasões", nome regional usado para designar terrenos públicos ou privados invadidos por trabalhadores para a construção de moradias, e que dão origem a novos bairros populares, sem nenhuma infraestrutura básica (LUCENA, 2016, p. 20).

Áreas onde havia equipamentos instalados pelo governo, como o Aeroporto Francisco Salgado Filho e a Cerâmica Estação Experimental, e onde estavam as colônias agrícolas, por exemplo, as colônias São Francisco, Apolônio Sales e a Fazenda Sobral, funcionaram como pontos de fixação dessas "invasões". Este foi o caso dos bairros da região da Baixada da Sobral, que surgiram em volta do Aeroporto Francisco Salgado Filho e da Fazenda Sobral. Os primeiros bairros da região da Baixada foram o Aeroporto Velho, Bahia, Palmeiral, Glória, Pista, Bahia Nova, João Eduardo I e João Eduardo II. Em 1983, outros bairros se instalaram ao redor: Ayrton Senna, Boa União, Boa Vista, João Paulo II, Plácido de Castro, Sobral (TORRES, 2018). A figura 3 apresenta os bairros que atualmente compõem a Baixada.

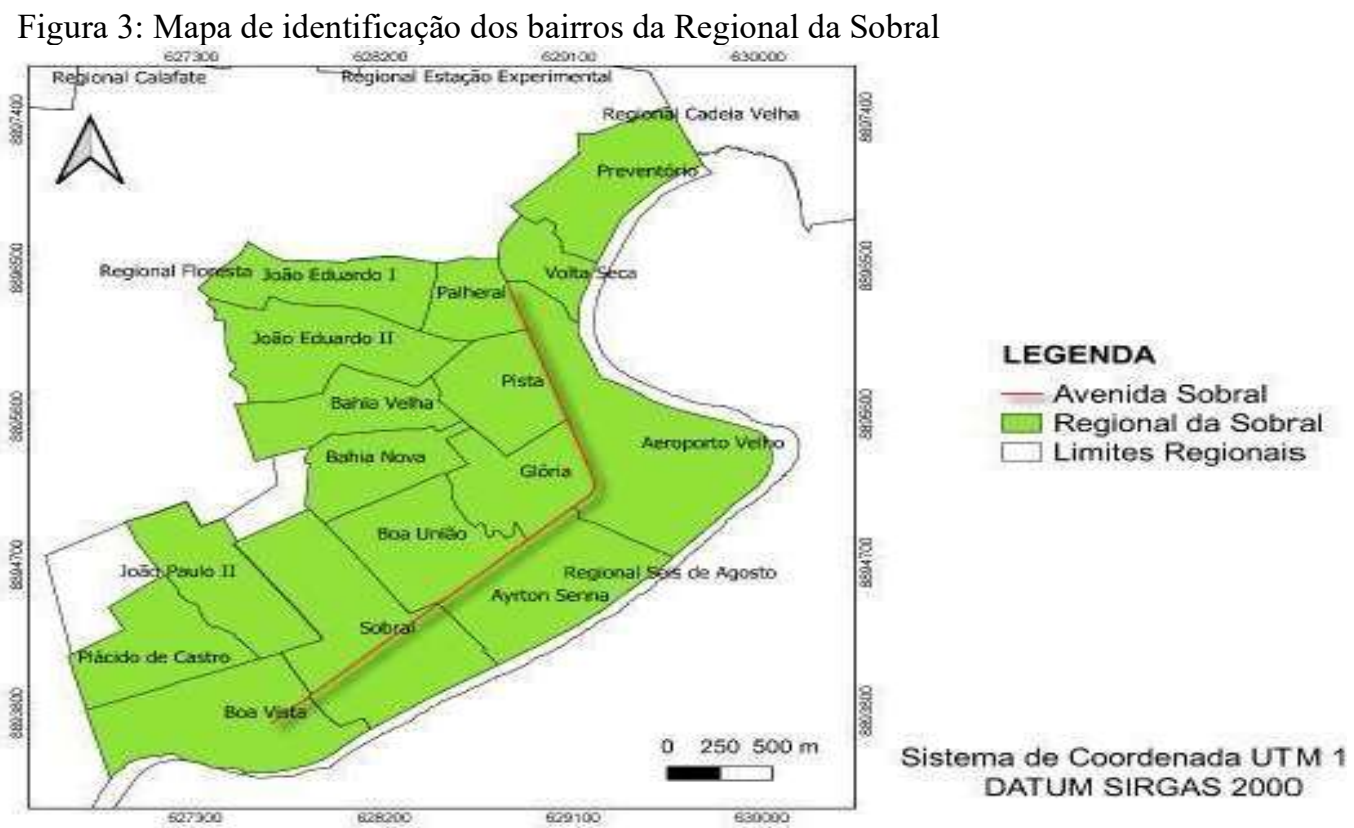

Fonte: LAGEOP apud Ferreira, 2020.

Grande parte da região da Baixada do Sobral se encontra na planície de inundação do rio Acre, assim como ocorre com outros bairros que tiveram sua origem ligada a ocupações informais. Dada sua localização, os bairros da Baixada são vulneráveis a inundações e foram afetados por todas as grandes "alagações" ocorridas em Rio Branco nas últimas décadas. 
Na capital acreana, a cota de alerta é de 13,5m, mas as cotas máximas do rio Acre vêm aumentando ao longo dos anos. De acordo com Mesquita (2015, p. 57), em 1988, o rio atingiu a cota de 17,12m; em 1997 e em 2012 o rio alcançou, respectivamente, 17,66m e 17,64m. Já na "alagação" de 2015, o rio registrou o maior nível da série histórica, chegando a 18,40m.

Grande parte dos bairros da Baixada da Sobral foi atingida na "alagação" de 2015. A água chegou a áreas da Baixada que não haviam sido inseridas nos registros anteriores de inundações. Mesmo as partes mais afastadas do rio foram afetadas, devido ao retorno da rede de drenagem. Conforme os relatos, muitos moradores precisaram ser retirados de suas casas, outros preferiram ficar nos imóveis inundados para se proteger dos "ratos d'água", termo comumente utilizado pela população e pela mídia acreana para se referir às pessoas que fazem furtos durante as inundações

1. Segundo um dos entrevistados:

[...] quando o pessoal saia e deixava as coisas, porque não dava de levar, eles roubavam. O vizinho de lá que tem uma loja, levou várias coisas, mas o resto colocou em um segundo piso que ele tem. Ele chegou, com dois dias depois não tinha quase mais nada, que levaram quase tudo. Eletrodomésticos, televisores e etc. (Entrevistado 1).

Durante a inundação, os moradores da Baixada que precisaram deixar suas casas tiveram que optar entre ir para abrigos temporários organizado pelo poder público municipal e estadual, alternativa criticada por muitas das pessoas entrevistadas, que a percebiam como pouco segura e confortável, ou ir para casa de parentes e/ou amigos.

\section{RESULTADOS E DISCUSSÕES}

Todos os entrevistados residem na Baixada da Sobral há vários anos. Em média, eles moram no bairro há 19 anos, mas alguns moradores estavam no local há apenas 6 e outros, há 50. Eles também residem próximo às margens do Rio Acre ou de córregos que existem na área e, em sua maioria, já sofreram dois ou mais episódios de inundações, relatando inúmeras perdas em virtude destes processos. Diante disso, e em consonância com o trabalho realizado por Moser (2005), que indica que o ambiente tem grande importância na formação da identidade das pessoas, verificou-se que os entrevistados compartilham o entendimento de que as

\footnotetext{
${ }^{1} \mathrm{O}$ uso deste termo pode ser visualizado nesta reportagem de 2015 :

https://www.ac24horas.com/2015/03/04/com-medo-dos-ratos-dagua-ele-nao-sai-da-casa-alagada/. Acesso em 04 jul. 2020.
} 
inundações são um fenômeno costumeiro na região, com o qual eles tiveram forçosamente que se adaptar. É praticamente consenso entre eles que a cheia ocorre todos os anos.

Em que pese este reconhecimento, excetuando-se uma entrevista, não houve relatos associados ao desejo de se mudar do bairro por conta das "alagações". Isso corrobora a leitura de Neto (2015, p. 176), que cita que em determinadas regiões do bairro Seis de Agosto, em Rio Branco, $[\ldots]$ os riscos provocados pelas inundações são encarados como algo que já faz parte do seu cotidiano, razão pela qual se opõem à remoção". O seguinte trecho, traz mais detalhes sobre esta indisposição dos moradores em se mudarem para outras áreas da cidade, apesar do risco recorrente de inundação:

[...] "a gente gosta do bairro, muitos aqui gostam. Tem outro vizinho que vai fazer um quarto com laje, para que se acontecer alagação, ele vai subir com a família para esse quarto, mas ele não quer sair, porque gosta [...] nós temos um presidente de bairro bastante presente [...] então a gente gosta né (Entrevistada $08)$ ".

Para lidar com o risco recorrente de inundações, os moradores tiveram que desenvolver estratégias individuais de prevenção. Vários adaptaram suas casas, que frequentemente são elevadas, possuem varandas mais altas e entradas protegidas por degraus, e móveis que são fáceis de serem transportados em momentos de inundação. Outras ações de prevenção citadas foram a elevação do assoalho, a construção de um segundo piso e a compra de baterias para gerar eletricidade e de barcos para possibilitar a mobilidade no momento do desastre.

Os moradores entrevistados também compartilharam o entendimento de que a inundação de 2015 foi um marco. Isso decorre da sua intensidade e de ter atingido alguns dos bairros da Baixada do Sobral que previamente a este evento não eram afetadas por inundações. A maioria das pessoas demonstrou estar mais alerta e preparada em relação a esses eventos extremos após 2015 e ter certo receio em relação ao período de chuva (verão, conhecido regionalmente como inverno amazônico). Nas palavras da entrevistada 07, quando [...] vem essa época de janeiro, fevereiro, época de muita chuva, eu já fico muita assustada. Eu fico todo tempo ali olhando o rio, porque eu não quero esperar mais, dentro de casa eu não fíco mais".

As entrevistas também evidenciaram que as inundações tiveram impactos sociais e emocionais variados. Assim, para a entrevistada 2, a inundação de 2015 "não foi ruim demais, porque alagou baixo [...]”. Já a entrevistada 07 expressou um sentimento totalmente diferente, pois a inundação não atingiu só sua residência, mas também ameaçou a saúde de um familiar, como demonstra o trecho a seguir: 
"É triste, muito triste. [...]. Você não dorme direito, a minha fillha na época estava gravida e ela correndo, pisando na água. Foi triste demais, eu pensei até que ia nascer doente ou minha filha pegar uma doença, foi terrível. A gente chorava abraçada com as outras, os vizinhos tudo triste, foi horrível. Sai do controle da gente (Entrevistada 07)".

Devido ao processo de ocupação informal, intenso e pouco planejado da região e aos problemas na garantia do direito à moradia adequada à população de baixa renda, há um número significativo de pessoas na Baixada da Sobral que vivem em áreas de risco, como em cima de córregos e em fundos de vale, o que eleva sua vulnerabilidade. Quando ocorre precipitação intensa e o nível do rio se eleva, o excesso de água acaba atingindo as áreas mais próximas aos rios (Aeroporto Velho, Ayrton Senna, etc.) e aos córregos. Outras pessoas entrevistadas habitam áreas mais elevadas ou distantes dos corpos d'água e contam que nunca tinham passado por situações de inundação até 2015. Quando foi pedido para uma moradora relatar tal evento, ela disse: "foi algo que não foi esperado na minha residência, mas era esperado no bairro na área mais baixa e, para a nossa surpresa, chegou na área mais alta do nosso bairro também (Entrevistada 08)".

Em relação à participação comunitária, nenhum entrevistado - nem mesmo os presidentes de bairros, que assumem papel de representação e de mediação entre os moradores e o poder público municipal - disse estar envolvido na gestão local de risco de enchente, em oposição ao que é preconizado pela literatura. Quando há inundação, eles dizem ligar para 190 ou esperar algum representante governamental aparecer, ao invés de tentarem estabelecer canais de articulação com o poder público local. Ademais, observamos que a decisão dos moradores sobre o que e como fazer diante das inundações é geralmente tomada por eles isoladamente, ou em conjunto com os familiares, amigos e vizinhos.

No que se vincula a dados sobre enchentes, todos os entrevistados falaram que se informam sobre a cota do rio Acre pelos jornais locais. Eles declararam não receber alertas, nem acessar fontes de dados oficiais sobre chuvas e nível do rio. Um problema com a forma pela qual os moradores se informam é que nas inundações o fornecimento de energia elétrica local é interrompido, com isso as pessoas não conseguem mais receber notícias pela televisão.

As entrevistas também apontaram que os moradores relacionam a ocorrência de inundações à falta de ação governamental, incluindo problemas com fiscalização e com a provisão de políticas habitacionais e de infraestrutura urbana, mas também à (ir)responsabilidade dos cidadãos, que, por exemplo, jogam lixo nos cursos d'água e desmatam as margens dos rios e córregos. Além da regularidade das inundações nos períodos chuvosos, a interferência humana foi citada em vários momentos como um elemento que potencializa os 
desastres, como por exemplo: a construção de moradias nos limites do rio Acre, as alterações nos corpos hídricos da região, construções mal projetadas de bueiros e bocas de lodo, responsáveis pela evacuação das águas e, principalmente, o depósito errôneo de lixo nas vias públicas e nos mananciais.

Alguns entrevistados comentaram, ainda, a presença de animais e insetos, e associaram estes vetores de doenças com a grande quantidade de lixo jogado pela população local no leito e às margens do córrego. Um presidente de bairro relata que os moradores [...] jogam muito lixo nos canais, onde é só para passar água, eles jogam pau, jogam geladeira, jogam pneu, jogam lixo e jogam tudo [...], [...] e sabe lá se aquela geladeira não tem um animal peçonhento, não tem uma cobra, não tem um escorpião ou os próprios ratos" (Entrevistado 06).

Com efeito, toda ação sobre o ambiente concerne não apenas o ambiente em sua dimensão física, mas igualmente a sua dimensão social. São inúmeras as razões que justificam a permanência desses sujeitos nas áreas de risco, as quais devem ser consideradas pelos órgãos públicos ao planejar medidas de prevenção e precaução dos desastres naturais.

\section{CONSIDERAÇÕES FINAIS}

A literatura sobre gestão de risco de desastres é consensual na leitura de que soluções para o problema de inundações, sejam elas preventivas ou mitigadoras, não devem se restringir a medidas estruturais e precisam promover a participação comunitária. Este esforço não pode estar descolado da percepção dos cidadãos sobre o risco de desastre socioambiental.

Diante disso, este artigo analisou a percepção dos moradores da Baixada do Sobral (Rio Branco-AC), uma área com histórico de inundação recorrente, para averiguar como eles percebem o risco, como se previnem em relação a ele e como se engajam (ou não) na governança local deste risco. A pesquisa evidenciou que os entrevistados entendem as inundações como um fenômeno cotidiano, não demonstram interesse em remoção e apresentam alta resiliência a eventos de enchentes, prevenindo-se contra esses riscos por conta própria e adotando diferentes estratégias.

Os resultados também indicaram que os respondentes têm reduzido acesso a dados oficiais sobre chuvas e níveis do rio e estão pouco inseridos no sistema local de governança de risco de inundação, o que reforça sua vulnerabilidade a este tipo de fenômeno socioambiental. Esta situação pode ser parcialmente compreendida pelos desafios institucionais e de capacidade relacionados com os órgãos locais que trabalham com esta temática, como a Defesa Civil 
municipal e estadual, bem como pelas dificuldades inerentes a processos de gestão de risco, os quais sempre trabalham com a incerteza de ocorrência de um evento.

De todo modo, a complexidade das iniciativas de gestão de risco demanda a busca por soluções coletivas, que ultrapassam os limites individuais e envolvam os moradores e o Poder Público no cumprimento de responsabilidades. Portanto, os órgãos responsáveis pela gestão local de riscos deveriam atuar no sentido de aprimorar a participação da comunidade nas reuniões e ações relacionadas aos riscos de inundações; bem como a implantação de um programa de educação ambiental voltado para a percepção dos riscos de inundações, redução de riscos e prevenção de acidentes.

\section{AGRADECIMENTOS}

Os autores agradecem aos pesquisadores Rachel Trajber e Mário Martins pela leitura de uma versão anterior do texto, bem como ao laboratório de Hidrologia, Meio Ambiente e Geografia dos Riscos da Universidade Federal do Acre, à Universidade de Warwick, ao Centro de Estudos em Administração Pública e Governo da Fundação Getúlio Vargas - Escola de Administração de Empresas de São Paulo e à Fundação de Amparo à Pesquisa do Estado de São Paulo (FAPESP) pelo suporte na realização da pesquisa que originou este artigo.

\section{REFERÊNCIAS}

ALVES, J. da S. Quando a Rua Vira Rio: Vulnerabilidade Socioambiental Urbana. 1 ed. Curitiba: Editora Appris Ltda, 2017.

BELTRÃO, R. E. V.; NOGUEIRA, F. do A. The Documentary Research in Recent Studies in Public Administration and Social Management in Brazil. In Conference Proceedings of the XXXV ANPAD Meeting. Rio de Janeiro, 2011.

BRASIL. Mapeamento de riscos em encostas e margens de rios. Organizadores: Carvalho, C.S., Macedo, E. S., Ogura, A.T.; Brasília: Ministério das Cidades; Instituto de Pesquisas Tecnólicas - IPT. 2007.

FERREIRA, I. E. S. da. Centralização, descentralização e novas centralidades em cidades médias: o caso do Subcentro da Avenida Sobral em Rio Branco (ACRE). Rio Branco: UFAC, 2020 .

FREITAS, C. M. de.; XIMENES, E. F. Enchentes e saúde pública - uma questão na literatura científica recente das causas, consequências e respostas para prevenção e mitigação. Ciência \& Saúde Coletiva, 17(6): 1601-1615, 2012.

FORESTI, A. J. Um arranjo interdisciplinar para gestão de risco de desastres socionaturais com base na engenharia de resiliência. Dissertação de Mestrado (Pós- 
Graduação de Engenharia em Civil) Universidade Federal do Rio Grande do Sul, Porto Alegre, 2015.

GRADIN, F. 'Chuva atípica' se repete há séculos no RJ; conheça histórias e imagens de grandes temporais. G1 RIO, 2019. Disponível em: https://g1.globo.com/rj/rio-dejaneiro/noticia/2019/04/10/chuva-atipica-se-repete-ha-seculos-no-rj-conheca-historias-eimagens-de-grandes-temporais.ghtml. Acesso em: 29 jun. 2020.

GUSMAN, M. Towards total disaster risk management approach. 2003. Disponível em: http:/unpan1.un.org/intradoc/groups/public/documents/apcity/unpan009657.pdf. Acesso em: 10 de maio 2020.

LONDE, L. R. de; COUTINHO, M. P.; DI GREGORIO, L. T.; SANTOS, L. B. L.; SORIANO, E. Desastres relacionados à água no Brasil: perspectivas e recomendações. Ambiente \& Sociedade, v. XVII, n. 4, 133-152, out.-dez. 2014.

LUCENA, G. Rio Branco. In: JACKS, N.; SILVESTRIN, C. B.; NOLL, G. Capitais brasileiras: dados históricos, demográficos, culturais e midiáticos. Curitiba: Appris, 2016. p. $18-26$.

MESQUITA, A. A. "Alagações": análise sobre a gestão de riscos em eventos de inundação no município de Rio Branco-AC. Trabalho de conclusão de mestrado em Desenvolvimento Regional - Universidade Federal do Acre, Rio Branco, 2015. 214 f.

MOSER, G. A psicologia ambiental: competência e contornos de uma disciplina, comentários a partir das contribuições. Psicologia USP, 16(1/2), 279-294, 2005.

NETO, D. J. A. de. A dinâmica das águas e das gentes: história, políticas públicas e percepção de riscos no Acre. Orientador: Léo Heller. 2015. Trabalho de conclusão do Doutorado Universidade Federal de Minas Gerais, Escola de Engenharia, 2015.

SANT'ANNA, E.; TAKAHASHI, F.; DIEGUES, L.; DUCROQUET, S.; São Paulo revive mesma enchente há 91 anos. Folha de S. Paulo. 2020. Disponível em: https://www1.folha.uol.com.br/cotidiano/2020/02/sao-paulo-revive-mesmas-enchentes-ha-91anos.shtml. Acesso em: 23 jun. 2020.

ANTOS, G. L. P. As enchentes no município de Rio Branco: a atuação da coordenadoria municipal de defesa civil sob a ótica da gestão de risco e da administração de desastres. 2006. 85 f. Trabalho de Conclusão de Curso (Especialização em planejamento e gestão em Defesa Civil)-Universidade Federal de Santa Catarina, Florianópolis, 2006.

SANTOS, F. A. dos; MENDES. F. M. M. É preciso debater o meio ambiente além de noticiar enchentes: uma análise sobre a cobertura jornalística da Agência na alagação. In: XVI Congresso de Ciências da Comunicação na Região Norte - Manaus - AM. 2017, p. 15. Disponível em: http://portalintercom.org.br/anais/norte2017/resumos/R54-0103-1.pdf. Acesso em: 26 de maio. 2020.

SILVA, S.; MARTINS, M.; \& SPINK, MJ, Percepção e hierarquia de riscos de inundação recorrente em área urbana regularizada: uma análise discursiva. Saúde em Debate. No prelo. 
SPINK, M. J. P. Viver em áreas de risco: tensões entre gestão de desastres ambientais e os sentidos de risco no cotidiano. Ciência e Saúde Coletiva, 19(9), 3743-3754, 2014.

TORRES, G. Conheça a Baixada da Sobral. Blog Fala Baixada, 2018. Disponível em: http://falabaixada.blogspot.com/p/conheca-baixada-do-sol_30.html. Acesso em: 04 de mai. 2020.

TRAJBER, R. Pensar fora da caixa: transição sustentável e resiliente. In Avaliação e monitoramento de políticas públicas de educação ambiental no Brasil: transição para sociedades sustentáveis. Orgs: RAYMUNDO, M. H. A., BIASOLI, S. A.; BRANCO, E. A.; SORRENTINO, M. Piracicaba: MH-Ambiente Natural, 2019.

TRAJBER, R.; OLIVATO, D.; MARCHEZINE, V. Conceitos e termos para a gestão de riscos de desastres na educação. CEMADEN EDUCAÇÃO, s.d.

VINUTO, J. A amostragem de bola de neve em pesquisa qualitativa: um debate aberto. Temáticas. Campinas, v. 22, n. 44, p. 203-220, 2014.

WISNER, B., GAILLARD, J. C.; KELMAN, I. Framing disaster: theories and stories seeking to understand hazards, vulnerability and risk. Routledge Handbook of Hazards and Disaster Risk Reduction. 


\section{ANEXOS}

\section{Anexo 1: Roteiro de entrevista prévia (semi-estruturada) - WP2/WPD no AC e SP}

Objetivo: compreender percepção inicial dos participantes sobre chuvas/alagação, estratégias de prevenção de alagação/enchentes e de resiliência depois dos desastres. Perguntas semelhantes serão refeitas com moradores depois de realizada a pesquisa WPD com vistas a analisar o seu impacto.

Participantes: moradores da área de estudo, interessante conversar com pessoas pouco engajadas com temas coletivos e com lideranças da região

Orientações a pesquisadores: apresentar aos moradores um resumo da pesquisa e do objetivo da entrevista, explicar que ela dura de 15-30 minutos e que iremos gravar o áudio, mas que a pesquisa é confidencial.

1. Qual seu nome e idade?

2. Onde você mora? Faz quanto tempo que você mora neste lugar?

3. Você já vivenciou muita alagação/enchente ou enxurrada aqui? Você poderia me descrever como é uma alagação/enchente típica aqui na região?

4. Quando houve alagações/enchente fortes, o que aconteceu depois?

5. Se você passou por alagação, você optou por ficar em casa, ou buscou outro local?

6. Caso tenha ido para o parque de exposição como foi sua experiência?

7. O que você acha que contribuiu mais para haverem alagações/enchentes?

8. Como você se previne de danos causados pela alagação/enchentes? E seus vizinhos?

9. Como você se informa sobre as chuvas e alagações/enchentes? 